\title{
Argument Structure in Arabic and English: Re-assessing Purity and Redeeming Hybridity
}

\author{
Faisal Said Al-Maamari \\ The Language Centre, Sultan Qaboos University University, Muscat, The Sultanate of Oman \\ E-mail: faisalf@squ.edu.om
}

Received: 10-12-2016

Accepted: 14-02-2017

Published: 01-07-2017 doi:10.7575/aiac.ijalel.v.6n.4p.104

Advance Access Published: April 2017

URL: http://dx.doi.org/10.7575/aiac.ijalel.v.6n.4p.104

\begin{abstract}
This study presents a contrastive rhetorical analysis of 20 argumentative Arabic and English editorials in argument structure. Samples were selected from two daily newspapers with equally wide distribution, and articles were written by their respective native writers. Both graphical and textual analyses captured the argument structure in terms of macro and micro arguments. A core finding is that the argument structure in the sampled editorials did not conform to the current predominant model of argument structure, which tended to polarize argument structure in terms of through or counter argumentation. The study contributes to the existing literature by defying the polarized traditional purity typology of argument structure frequently cited in the literature, and emphasizes a more dynamic hybrid model to understanding and analyzing arguments in general and in Arabic and English specifically. Additionally, the study of the professional genre of editorails has implications for academic writing and second language writing pedagogy by sensitizing foreign language learners to existing models of argument structure and possible ways to structure their arguments in the target language.
\end{abstract}

Keywords: Arabic, argument structure, contrastive rhetoric, editorials, English, newspaper genres

\section{Introduction}

Current scholarship in relation to argument structure in Arabic and English has examined newspaper editorials as one form of professional genres. This literature has pointed out the through and counter text structure of Arabic and English editorials. However, the current research is overly simplistic and limited in its characterization of the text structures. Therefore, the aim of this paper is to challenge the predominant view purporting to classify arguments in either-or terms, and sets out to present a more complex, yet more dynamic, description of argument structure in Arabic and English. After a review of the pertinent literature, the paper proceeds to describe how the study addresses this important area of contrastive rhetoric.

\section{Contrastive rhetoric: Background}

Robert Kaplan's 1966 seminal article in which he examined some 600 ESL essays written by students from different cultures-Arabic, Chinese, French, Japanese and Russian — set the first footsteps of contrastive rhetoric as a field of study. Kaplan's basic assumption was that thought patterns and logic differed across cultures which in turn affected languages in shaping and presenting these cultures and construing reality. He pointed out that English rhetoric is "essentially a Platonic-Aristotelian sequence" evolving from ancient Greece and Roman, and is characterized by linear progression of ideas. In that study, Kaplan concluded that different cultures approach writing differently and he provided diagrammatical representations whereupon he suggested that whereas English speakers write in a straight line, Asians write in circles, and still others in zigzags. However, Kaplan's approach was heavily criticized, and his diagrams thought of as "more intuitive than scientific". Still that study was "valuable in establishing contrastive rhetoric as a new field of inquiry" (Leki, 1991, p.123).

Not only was criticism poured on Kaplan's work, the whole realm of contrastive rhetoric was subject to severe criticism. It was criticized for being prescriptive, with the over-rise of models in ELT textbooks and process writing approach proponents equating contrastive rhetoric with the product-based approach to writing pedagogy (Zamel, 1983; Raimes, 1983). However, the product approach does not surpass the sentence, and deals with linguistic elements within its boundaries whereas contrastive rhetoric research focuses on larger issues of organization where a deficiency in them leads to disappointment and a total misunderstanding of the message being communicated. For another, contrastive rhetoric studies with their focus on large patterns of discourse arrangement are complementary to process writing rather than contradictory. Despite all this criticism, contrastive rhetoric still enjoys a prominent place in writing pedagogy, and insights form CR continue to nourish theory and practice. Grabe and Kaplan (1996) summarize the territory after approximately 25 years of research:

[Contrastive Rhetoric] goal is to describe ways in which written texts operate in larger cultural contexts ... It is interested in questions relating to the description of various genres - the question of whether or not these genres 
occur in various languages, and the questions of what constitute evidence and what is the best arrangement for

such evidence in various genres as they occur in different languages. (p. 179)

Therefore, CR is not normative aiming to lay preference of one language over another. After Kaplan (1966), steady progress has been achieved especially with the emergence of discourse studies as a new area of investigation in the 1970s and later in the 1980s (e.g., de Beaugrande, 1980). This has ignited fresh interest in contrastive rhetoric. Discourse analysis has begun to explore in depth areas such as coherence, cohesion and organization patterns of texts. Studies have been conducted among languages, genres (ESL essays, business letters, etc.), text types (narration, argumentation, etc.) and in both academic writing (Drid, 2014) and professional genres (Abbadi, 2014).

\section{Professional writing}

According to Connor (1996), "Professional writing takes place in business, newspaper offices, governmental agencies and other work places" (p.137). It, therefore, differs from academic writing in that whereas this latter is more likely to address one discourse community of academics with roughly the same expectations, professional writing requires dealing with different audiences. Work in different professions, each with its special characteristics and genres, requires competence in these genres and sensitivity to their audiences if successful communication is to result. Flowerdew (1993) points out that "Genre is an important concept in professional communication because members of individual professions, or 'discourse communities', will share common purposes of communication, or genres” (p.305).

The genre of newspaper language comprises a vital part of professional writing. Newspaper articles are read by massive mass audiences. Therefore, the study, and hence the analysis, of newspaper language is important and has worthwhile applications for the classroom (Bell, 1991). First, newspaper texts are readily available and accessible to the large community of individuals. Second, newspaper language is part of everyday life. Also, its characteristics of fast spread, dissemination and popularity distinguish it from any other kind of print. More importantly, language and thought presented are authentic and contextual in that they are intended for mass public consumption.

The numerous studies undertaken in the various genres of professional writing attest to its importance as a form of communication. Research has been carried out in business writing (Jenkins and Hinds, 1987; Ten, 1986), legal discourse (Bhatia, 1993), and editorials (Dantas-Whitney and Grabe, 1989; Tirkkonen-Condit and Lieflander, 1989).

\section{Editorials}

Editorials are a type of professional newspaper writing. Bell (1991) classifies everything in newspapers other than advertising under the umbrella of 'editorial'. He distinguishes between three main categories of editorials: service information, news and opinion. The first two are informative reporting on such themes as sports results, weather forecast, share prices, reports of accidents, events and features. Opinion editorials on the other hand are argumentative “"leaders - a statement of the newspaper's own views on an issue" (Bell, 1991, p.13) although they do not necessarily reflect the views of the newspaper.

Connor (1996) recognizes that even though ESL or EFL students will hardly need to write editorials as part of their learning, editorials "reflect national styles regarding modes of persuasion" (p.143); further, lessons may be learned from the analysis of editorails for the benefit of EAP and ESP (Malah, Tan \& Rashid, 2016). Although the genre of editorials does not appear in syllabuses, the argumentative style they exhibit does. Moreover, editorials are easily accessible and students are readers of them (Bell, 1991; Connor, 1996). Reported in Connor (1996), the study done by TirkkonenCondit and Lieflander-Koistenen (1989) compared editorials of English, Finnish and German. Their main aim was to compare "the strength and placement of the main claim or argument of an editorial" (p.142). They discovered that German editorials tend to place the argument at the outset, even much more frequently than their English counterparts do. However, Finnish editorials were found to have no argument statement simply because the texts sampled happened to be of an informative nature.

\section{Arguments and argumentation}

Arguments are used in spoken and written discourse and are common in both Arabic and English. Hatim (1997) points out that argumentation among Arab rhetoricians dates back to the eighth century AH (14th century) in the work of Qudaama b. Ja'far, in his book Naqd al-Nathr, "The Criticism of Prose” (pp. 48-80). Similarly, the English philosopher Toulmin (1969) identifies a three-part argument structure: (i) claim which is the statement argued for or against, (ii) data which are support for or against the claim, and (iii) warrants which are "rules, principles, inferences, licences ... [rather than] additional items of information" (p.98). Here, warrants act as transitory statements from the data provided to the claim first argued. Argumentative texts differ from expository texts in a very significant way. The function of argumentative texts is "to promote the acceptance or evaluation of certain beliefs or ideas as true v. false, or positive v. negative" (de Beugrande \& Dressler, 1981, p.184 cited in Hatim, 1991, p.191) with "conceptual relations such as reason, significance or opposition becoming naturally meaningful and frequent" (Hatim and Mason, 1997, p.109). As such, the other party's (or opponent) views/opinions are always borne into account during the writing. Expository texts, by contrast, are "non-person oriented" (Jenkins and Hinds, 1987, p. 330). They attempt to analyze events/topics into their constituents, describe situations or recount happenings (Hatim, 1991, 1997).

In his studies of advanced EFL Arab students' persuasive essays, Drid (2014) found that out of 104 essays, 50\% followed the through-argumentation style while $47.11 \%$ were of the counter-argumentation mode. Also, in his textual analysis of the linguistic strategies employed in the structure of arguments, Abbadi (2014) reported 10 Arabic editorials following through-argumentation and the 10 English editorials employing counter argumentation. 


\section{Types of argumentation}

Through his translation research into Arabic and English, Hatim $(1991,1997)$ differentiates between two basic forms of argumentation: (i) through-argumentation and (ii) counter-argumentation. "A through-argumentation text is characterised by extensive substantiation of an initial thesis" (1997, p. 189). This means that the writer's thesis argued for or against is supported by evidence. This evidence usually indicates why and/or how what the writer has claimed in the thesis is true or false. "A counter-argumentation text, on the other hand, involves the rebuttal of a cited thesis, followed by a substantiation of the rebuttal and a conclusion" (p.189). Counter-argument is further subdivided, according to Hatim (1991, 1997), into two categories: the Balance and the Lop-sided argument. In the Balance argument subtype, the text producer may opt to mark the transition from a claim to a counter-claim explicitly or implicitly. In the explicit counter-argumentation subtype, the writer signals the transition very clearly with adversative conjunctions such as "But, However, etc.". The implicit counter-argumentation pattern is a thesis-rebuttal-substantiation, but without adversative signals. By contrast, in the Lop-sided argument subtype, the text producer embeds an explicit concessive markers such as although, while, despite, etc. in a proposition in order to aid in the anticipation of the counter-argument. In sum, it is a thesis-rebuttal-substantiation pattern with a concessive conjunction attached to the claim. The concessive plays an important part in preparing the reader for the counter-claim which is to follow.

Hatim (1991) points out that counter-argumentation, particularly the Balance subtype, is preferable in English. However, in Modern Standard Arabic, through-argumentation is preferred even though counter-argumentation of the Lop-sided subtype was in use at one point in time. Figure 1 (Hatim \& Mason, 1997, p. 111) below summarizes the order of preference of argumentation text type in Arabic and English.

Arabic

A. Through-argumentation

B. The Lop-sided Argument

C. The Balance counter-argument (always explicit)
English
A. The Balance counter-argument
B. Through-argumentation
C. The Lop-sided Argument

Figure 1. Preferred Order of Mode of Argumentation in Arabic and English

However, according to Hatim the Arabic order may be true only of the current literature. There is evidence that counterargumentation of the Balance format existed in Ancient Arabic rhetoric, and pioneers like Qudaama (died in 337AH.) and Al-Sakaki (1937) contributed considerably to this logic of development. The paper aims to address a core concern in the literature in relation to argument structure. Although a careful reading of Hatim and Mason (1997) indicates that the authors have described the possibility that a text may display more than one argumentation subtype, there are two concerns:

- the above model (Figure 1) is overly restrictive and does not account for the fluidity of text types in the same texts as well as across; and

- current scholarship in argument structure in contrastive rhetoric consistently shows and describes a polarized view of argumentation type, either as through or counter (e.g., Abbadi, 2014 \& Drid, 2014, and others).

\section{The study}

This paper is part of a larger MA study which aimed to study the macrostructure, argumentation mode and cohesion of 20 Arabic and English editorials having an argumentation text type. This paper focuses only on argument structure and addresses two research questions:

\section{What argumentation models do the Arabic and English editorials of the argumentation text type exhibit?}

\section{What macro-structural and linguistic features do these editorials exhibit?}

This is a contrastive rhetorical analysis study that explores the bigger structure of argumentative texts, and does not focus on sentential level qualities such as grammar and lexis, only in relation to how these contribute to the larger area of argumentation. Further, even though the original study was completed more than 15 years ago as an MA thesis in a British University, the paper offers a fresh look with a more robust methods of analysis and sharper theoretical orientation to characterize the argument structure.

\subsection{Sample selection}

Grabe (1987) and Bell (1991) caution that to undertake a contrastive rhetorical study, the researcher needs comparable entities or subgenres. In the process of selecting the samples of newspaper editorials form both Arabic and English for analysis, I considered a number of precautionary notes often sounded in the literature. Firstly, it is not totally reliable to base one's comparison on what a language is thought to be, or how specific writers write. Braddock (1974) argues that native writers do not necessarily write in a straight line: commencing with a topic sentence, then supporting details, then a concluding remark. Real samples have to be gathered from both or all languages under comparison. In this study Arabic and English editorials were compared. Secondly, the function of language gathered for analysis must be similar or comparable. Grabe (1987) stresses that to achieve reliability of findings, analysis must compare samples of the same text type across cultures. The chosen samples exhibited one genre (editorials) and one text type (argumentation). Extra attention was exercised to avoid the trap Tirkkonen-Condit and Lieflander-Koistenen (1989) fell into when they 
inappropriately chose informative, as opposed to argumentative Finnish editorails, as they did for the French and English editorials. Thirdly, a researcher undertaking a comparative study has to ascertain that the compared genres, text types, etc., do exist in both languages and are popular among the speakers of each language. Leki (1991) concedes that comparison of texts across cultures depends upon the frequency of such genres and types in the community for whom the discourse is derived. Both genre and text type chosen are common among Arabs and the English.

Table 1. Titles of Arabic and English Editorials

\begin{tabular}{|c|c|c|c|}
\hline A. 1 & $\begin{array}{l}\text { Statues destruction and the process of decision- } \\
\text { making within Taliban }\end{array}$ & E.1 & $\begin{array}{l}\text { The US pulls back: The Clinton approach has } \\
\text { been ditched }\end{array}$ \\
\hline A. 2 & About the problem of natural treatment & E.2 & $\begin{array}{l}\text { Simply the wrong policy: Bush's energy plans } \\
\text { are for a different era }\end{array}$ \\
\hline A.3 & We and the world tourism publicity about Egypt & E.3 & $\begin{array}{l}\text { Passion play: Easter offers secular inspiration, } \\
\text { too }\end{array}$ \\
\hline A. 4 & The new Arab League & E.4 & $\begin{array}{l}\text { When frustration erupts: The lesson of Oldham: } \\
\text { Politics must listen }\end{array}$ \\
\hline A.5 & Is it freedom or dissolution? & E.5 & $\begin{array}{l}\text { Violence doesn't pay: Prague lesson is that } \\
\text { reform works best }\end{array}$ \\
\hline A.6 & Rules to protect our civilization & E.6 & $\begin{array}{l}\text { The truth is still hidden: Crucial questions } \\
\text { persist about Lockerbie }\end{array}$ \\
\hline A.7 & The Israeli American alliance & E.7 & In a search of a new map \\
\hline A.8 & Is this ... the start of collapse? & E.8 & $\begin{array}{l}\text { A journey to nowhere: Vetoed: A mission that } \\
\text { might have helped }\end{array}$ \\
\hline A.9 & $\begin{array}{l}\text { Journalists and the protection of their rights in } \\
\text { electronic property }\end{array}$ & E.9 & $\begin{array}{l}\text { A failure of leadership: Sharon and Araft must } \\
\text { stop posturing }\end{array}$ \\
\hline A. 10 & There is life for you ... in dialogue!! & E.10 & $\begin{array}{l}\text { Supping with Sharon: Rules for dealing with } \\
\text { Israel's new leader }\end{array}$ \\
\hline
\end{tabular}

Bell (1991) identifies three other conditions which must be satisfied in order to gather valid and reliable sampling of media language: genres, outlets and outputs (p.12). Genre was explained earlier. Outlets are "the publications, television channels or radio stations which carry the content" (p.12). Thus both samples of editorials were collected from two quality daily newspapers with high circulation: Ahraam (published in Egypt, read across the Arab world, uses modern standard Arabic, available on the internet) and The Guardian (published in the United Kingdom, read across the English speaking community, uses standard English, available on the net). Outputs are "what the media outlets producespecific newscasts, advertisements, or programmes - and the time period to be covered" (p.12). All editorials come from the main publications of these newspapers, years 2000 and 2001. The topics selected were of social and political nature discussing local issues or concerns in relation to the international arena (Table 1). While this attempt to standardize sampling procedure cannot be claimed to be perfect, it will, nevertheless, reduce randomness in sampling and boost comparability.

\subsection{Methods of analysis}

In order to address the first research question to identify the argument structure and the second research question in relation to linguistic and macro-structural strategies, two methods were used: (i) Hoey's lexical signaling, and (ii) a content analysis outlining technique. The argumentation style was captured in the editorials using lexical signaling, which is "the author's/speaker's explicit signaling of the intended organisation" (Hoey, 1983, p. 63). Lexical signals can be a word, a phrase, a clause or even a sentence. Therefore, lexical signaling is the exploitation of signal words apparent in the text to arrive at the relation between its sentences. Hoey $(1983,1994)$ argues that lexical signaling should be the first step to use to analyze structure of any text because they are naturally available in the text. In terms of broadly analyzing text structure, the whole analysis was guided by Hatim (1991) overall framework for analyzing arguments, reviewed earlier.

After the selection of the 10 Arabic and 10 English editorials in the manner described above, analyses proceeded as follows. The analysis undertaken in the MA thesis was re-examined more precisely. Articles were re-read thoroughly several times, signal words were noted, and each editorial text was broken down into the main argument, its macro and microarguments. This whole process was reiterated a number of times before a final picture on text structure was achieved. This enabled the analysis to identify the structure of the text and its argumentation patterns. The breakdown of the 10 Arabic and 10 English editorials is presented in appendix 1 (Arabic) and appendix 2 (English). Two methods of outlining were employed to dissect the argument structure in the editorails: tabular representation for through/counterargumentation, and diagrammatical representation in case of the editorials showing a combination of two or more argumentation styles. Samples are presented inline to illustrate the core findings in relation to the research questions. 


\section{Findings}

The findings are presented in this section in relation to each research question. Graphical data is supplemented with qualitative textual commentary where appropriate.

Research Question 1: What argumentation models do the Arabic and English editorials of the argumentation text type exhibit?

This question is addressed in two ways. One is to describe the editorials in terms of the predominant argument structure they exhibit (Figure 2). The second is to characterize the editorials in terms of the counter-argumentation style to which they subscribe.

Figure 2 below shows the modes of argumentation captured in the 10 Arabic and 10 English editorials. Specifically, the figure shows three modes of argumentation style. These are the classic through-argumentation and counterargumentation, and a third hardly-cited mode, which I term 'hybrid', which is a combination of the two classic models.

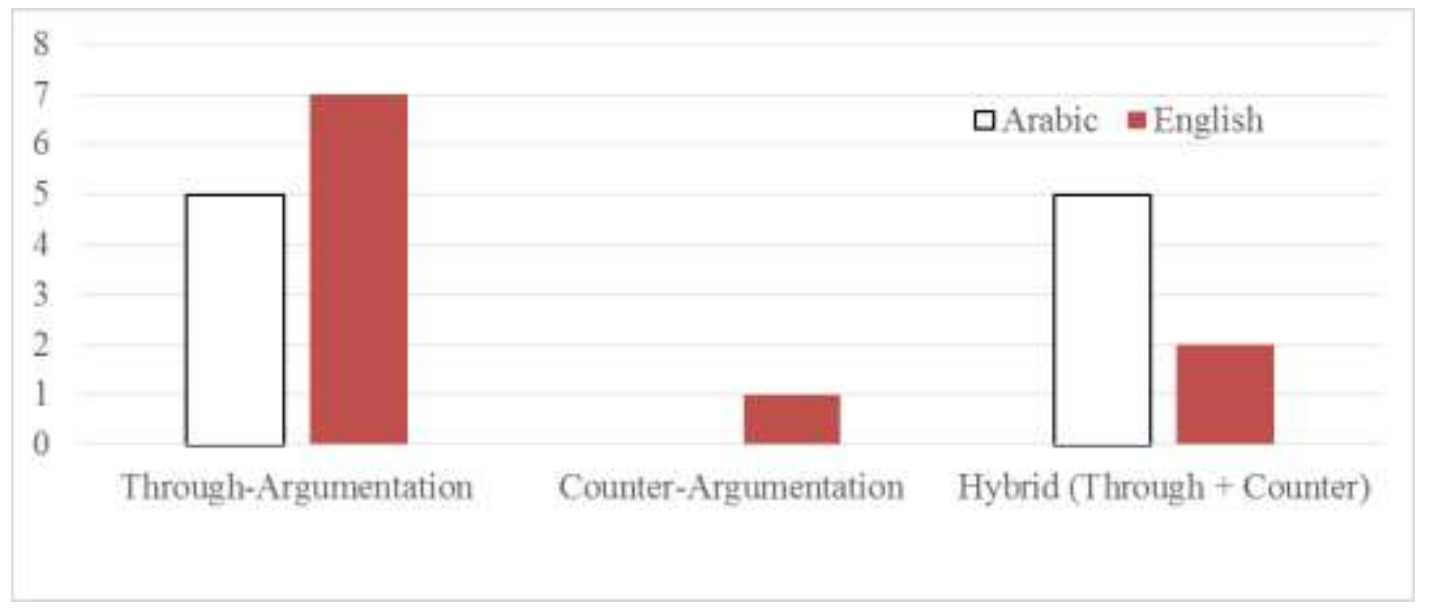

Figure 2. Distribution of Three Argumentation Styles in the 10 Arabic and 10 English Editorials

The Arabic editorials comprise 50\% (5 out of 10) through-argumentation and 50\% hybrid; none of the editorials exhibited counter-argumentation only prototype. In contrast, the English editorials comprise $70 \%$ throughargumentation, $10 \%$ counter-argumentation and $20 \%$ hybrid. What is particularly interesting here is the emergence of the hybrid model, which has been underplayed in the contrastive rhetoric literature and the existing model of argument typology (Hatim and Mason, 1997) — a point we will return to at the end of the paper. The distinguishing qualities of hybrid editorials shall also be discussed in great detail later in the paper.

Figure 3 explores further the counter-argumentation types in both the Arabic and English editorials. It is a count of the editorials that exhibit one or more type under counter-argumentation in predominance. As such, it is the number of editorials under Counter-Argumentation and Hybrid in Figure 2 above.

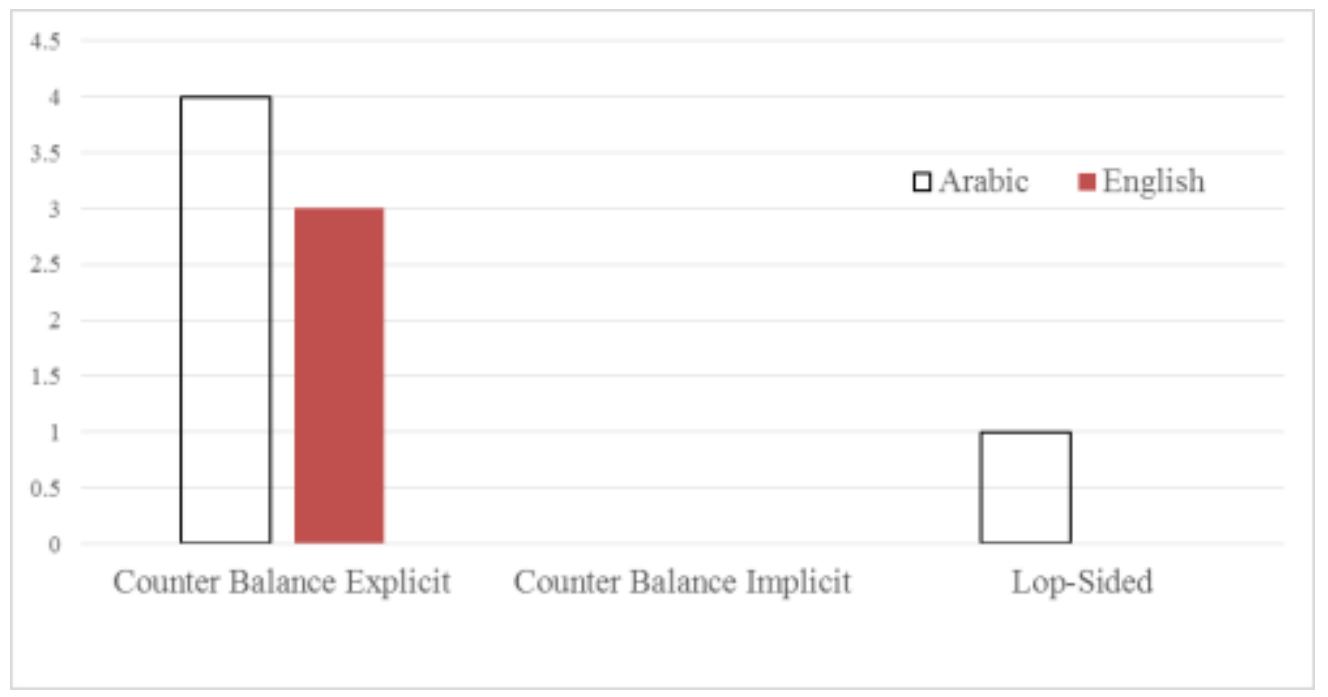

Figure 3. Number of Editorials Exhibiting any Counter-argumentation Subtype in the Arabic and English Editorials

Figure 3 shows the existence of the counter explicit balance mode of argumentation in 5 Arabic and 3 English out of the 20 editorials, with a total percent representation of $40 \%$. Further, one English editorial reflected one counter implicit balance mode of argumentation in a predominantly explicit balance argument structure and is not shown in Figure 3, and one Arabic editorial showed a lop-sided mode of argumentation. In sum, Figures $2 \& 3$ demonstrate the qualities of the Arabic and English editorials in regards to the large structure of their argumentation organization. Plotting these 
findings against Hatim's $(1991,1997)$ model of preferred order of argumentation styles for Arabic and English yields the following tabulation (the number between brackets tallies with the number of editorials following each mode of argumentation):

\section{Arabic}
A. Through-argumentation (5)
B. The Lop-sided Argument (1)
C. The Balance counter-argument (4)

\section{English}
A. The Balance counter-argument (3)
B. Through-argumentation (7)
C. The Lop-sided Argument (0)

The English and the Arabic editorials examined here do not conform to Hatim's model (1991, 1997). In the cited model in the literature, in English balance counter-argumentation is purported to come in first place, and in the current tabulation through-argumentation is in first place. In the cited model in the literature for Arabic editorials, the lop-sided argumentation is second in place; however, in the current findings, the balance counter-argumentation is second. Subsequently, Hatim's model of argument structure will be compared to the findings of this study in terms of the microarguments.

Research Question 2: What macro-structural and linguistic features do these editorials exhibit?

As was indicated above, this section addresses the 20 Arabic and English editorials in terms of the microstructure and internal linguistic strategies. In this section, sample editorials following through-argumentation, counter-argumentation (balance explicit) and lop-sided are presented with commentary highlighting key strategies.

\section{An example of through-argumentation (English)}

Text E4 presents a thesis with three head nouns citing three core arguments, each of which is then explicated in a paragraph.

\section{TEXT E4}

... In the 1990s in the deprived pockets of Oxford, Leeds and Cardiff; a decade earlier in Brixton, Southall and Toxteth. Now, as then, it is the same combustible mix: race, poverty and a distrusted local police force.

... For Saturday's events did not come out of nowhere ... The first is poverty. ...

... The term "Asian" is too broad to be useful: there are so many different communities group under that umbrella. ...

... Those facts have been aggravated in recent years by the factor that is often central to any discussion of race in Britain: policing. ...

The three arguments as well as the cohesive devices introducing and enumerating the three arguments (i.e. the first, the term, by the factor) are highlighted above.

An example of counter argumentation (English)

In Text E8, the writer raises a Question about a Situation, which is that the US has vetoed a resolution to send a UN observer force into the Occupied Territories, justifying their position that such force 'does not accord with "political reality"'. The Question the author poses is 'To which political reality does Mr Cunningham refer?' Distancing $\mathrm{him} /$ herself from these claims through the use of 'perhaps', the writer then cites three claims that could be voiced by the public as clear from the text skeleton below:

\section{TEXT E8}

Claims cited

- $\quad$ The reality of a dead Jewish baby and yet another slaughtered Arab child, perhaps.

- $\quad$ Perhaps it is the political reality that encourages the suicide bombers of Hamas and Islamic Jihad to commit daily atrocities with the aim of driving Israel into insupportable overreaction.

- Or perhaps it is the political of the Amman Arab summit which ended yesterday and which, seem from the Arab street, once again failed to provide a strong, united lead in defending Palestinian rights.

The writer next presents the answer to the question as he/she sees it. He/she starts with a counter claim signal 'No', and then proceeds to substantiate this Opposition in three ways, signaled by the word "another" two times as is clear below.

No, the political reality to which Mr Cunningham refers is that captured by official photographers at the White House last night when Mr Sharon turned the charm on George Bush. The US veto was one result of that equal encounter. Another .... . Yet another, more fundamental still, .... .

In turn, the word 'No' in the above text and the use of the word 'But' in texts E2 and E10 are both separate from propositions and syntactically close-category words.

\section{An example of lopsided (Arabic)}

Text A4 has a hybrid macrostructure comprising through-argumentation and the lop-sided subtype of counterargumentation to organize its arguments. The focus here is on the four lop-sided arguments presented. These are signaled by 'although (3)' and 'although it may seem'. Instead of presenting the opponent's claim/argument/stance 
indirectly or implicitly, the writer prepared readers that a counter-claim was inevitable and he/she prepared them to accept the counter-claim he/she was going to present.

\section{TEXT A4}

Although we trust Amro Moosa very much on his ability to revitalize the Arabic League, we must not put on him more load than he can take because the Secretary General and the Arabic League capabilities do not surpass the political boundaries of the Arabic countries.

The above counter lop-sided argument has a specific arrangement:

A concession + opponent's cited thesis + comma + writer's counter-claim + writer's substantiation of counter claim

None of the English editorials exhibited the above text type, which in English would normally be marked by devices such as "whereas" or one of the concession variants such as "though, even though, although".

\section{The concept of hybridity in argument structure}

Since the paper's main goal is to emphasize hybridity which is absent in the currently cited literature model of argument structure, this section expends space to this concept. To explore the hybridity in the mode of argumentation for the Arabic and English editorails in greater detail, two graphs are plotted in Figure 4 and Figure 5. Figure 4 is graphed to depict the number of microarguments in each editorial by language type and their distribution across argument types, and Figure 5 examines the seven hybrid editorials in relation to the combination of argumentative subtypes which they display.

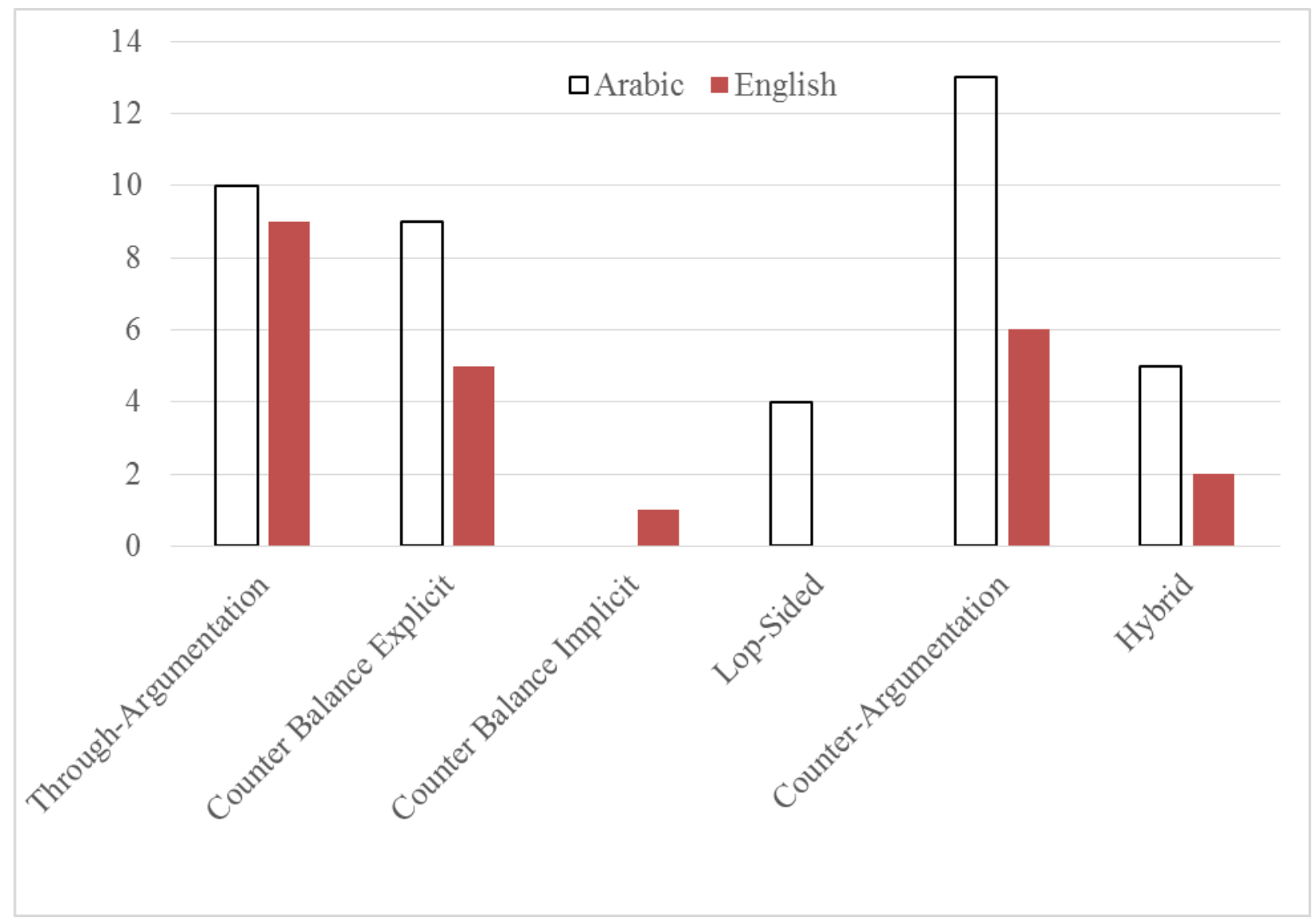

Figure 4. Microarguments Inside the Argumentation Macrostructure in Arabic and English Editorials

As was indicated earlier, seven editorials fell in the hybrid domain in relation to the macroarguments. This is indicated by the further left-hand side columns in Figure 4. Two points are important to note about the rest of the chart, which shows distribution in argument microstructure. First, the Arabic argumentative editorials had 4 lop-sided microarguments in one editorial, whereas English had none. The same could be said about the counter balance implicit mode of counter-argumentation in favour of English. Further, once again if we plot the number of microarguments by type (through, counter explicit/implicit and lop-sided) to Hatim's $(1991,1997)$ proposed model, the cited model in the literature does not obtain.

Arabic
A. Through-argumentation (10)
B. The Lop-sided Argument (4)
C. The Balance counter-argument (9)

English
A. The Balance counter-argument (5)
B. Through-argumentation (9)
C. The Lop-sided Argument (0)

Considering article length which was not calibrated for this microargument analysis, a naked-eye examination of the 
articles indicates that article size is in favour of the Arabic articles. Therefore, the above finding should be cautiously upheld and is in need of further controlled exploration.

To continue further with discussing the textual properties of the hybrid Arabic and English editorials in terms of microstructure, Figure 5 is presented to gauge the different combinations of through and counter-argumentation that the hybrid texts display.

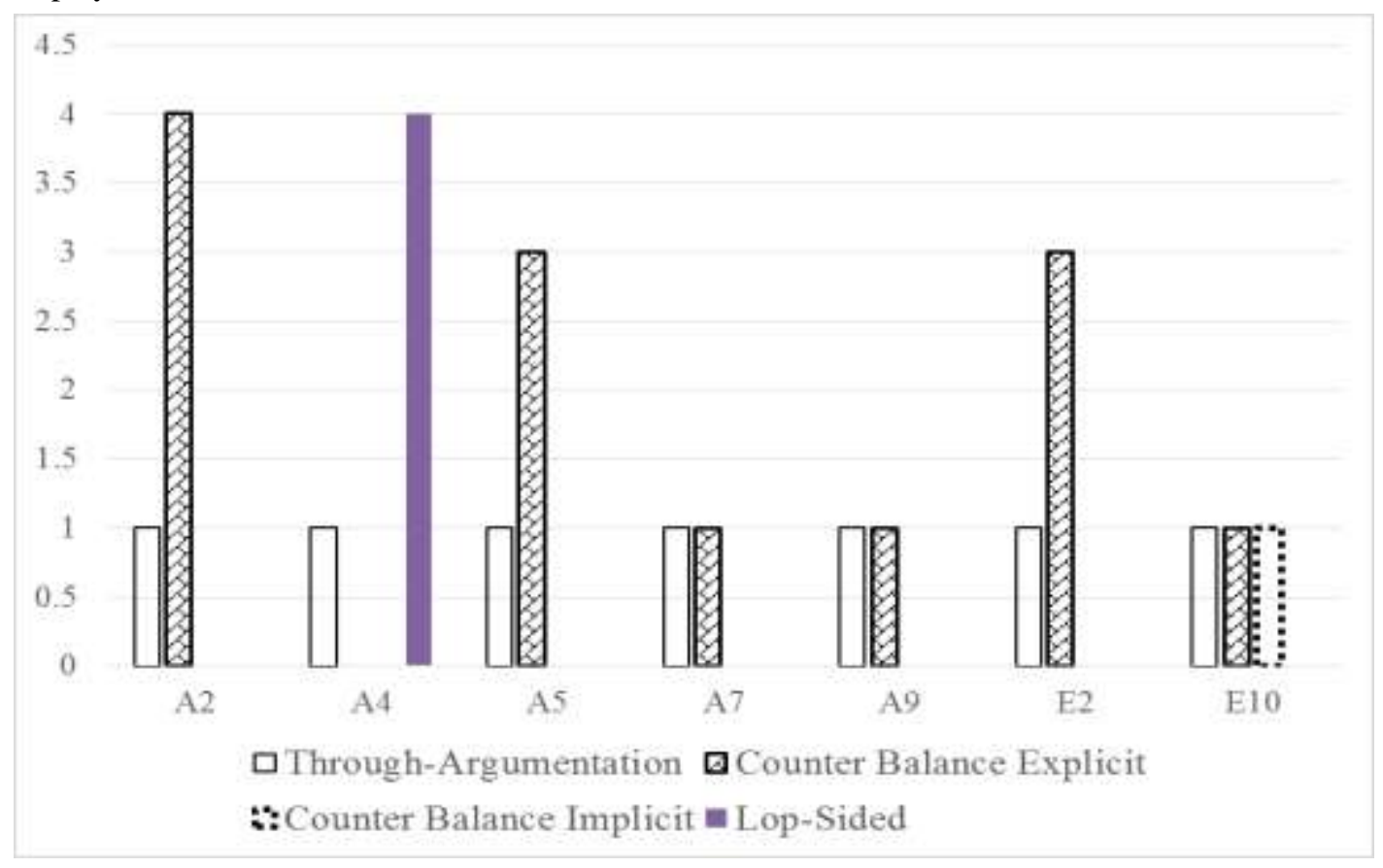

Figure 5. Hybrid Argumentation Style Distribution in the Arabic and English Editorials

As was indicated earlier, a total of seven editorials qualified into the hybrid mode of argumentation, 5 Arabic and 2 English. The most common type of hybridity in these editorials is through and explicit balance, with 4 out of possible 5 Arabic editorials showing this blend and two out of two in the case of the English editorials. One Arabic editorial (A4) showed hybridity of through and lop-sided, and one English editorial showed three: explicit and implicit balance type together with the through mode of argumentation. Coupled with the quantitative analyses described above, I present an example hybrid model from the Arabic editorials' sample for commentary.

An example of hybrid argument (Arabic)

Text A2 below is an Arabic argument of the hybrid type. Through arguments are marked by dotted brackets and counterarguments are marked by braces. In the through-argument sub-section, the writer states a clear thesis that 'The problem is practitioners of natural treatment do not admit that they are ancillary to the medical profession'. Subsequently, she substantiates this thesis with five arguments. In the counter-argument sub-section, which is an explicit subtype, the writer explicitly presents a statement of purpose, namely that 'Come with me to respond to their claims one after the other' following this with a presentation of four claims which she subsequently sets out to oppose, each at a time.

\section{TEXT A2}

Thesis to be argued: The problem is practitioners of natural treatment do not admit that they are ancillary to the medical profession.

I Substantiation 1: In the past they demanded that a final year added to their program, and were give this final year.

Substantiation 2: In the past, the demanded their institute change into college, and they were given this.

Substantiation 3: Now they are making protests to work without the supervision of the medical doctor, which is a catastrophe if it is allowed to happen.

I Substantiation 4: Worldwide, the medical team is headed by a medical doctor who has first responsibility for the welfare of patient.

Substantiation 5: Practitioners in natural treatment are ancillary staff as the case is in the UK and US

Thesis to be opposed: Practitioners of natural treatment study six years, one year less compared to students in College of Medicine

Opposition: This is fabrication.

Substantiation 1: They study four years and another training year

Substantiation 2: Medical doctor has to study 10 years

Thesis to be opposed: Practitioners of natural treatment claim to be prepared to work under any doctor but a medical doctor.

Substantiation: Specialist or medical doctors do not know the work of natural treatment practitioners

Thesis to be opposed: They say that their certificates are not equalized when they travel to the US. 
Substantiation 1: The US system requires that the certificates of medical doctors be equalized

Substantiation 2: Other professions ancillary to medical doctors do not get their certificates equated.

Thesis to be opposed: They say ministerial decisions stipulate that they should be treated separately from medical doctors

Substantiation 1: Ministerial decisions are not the law, and the State Council declared that natural treatment practitioners are under the assignment of medical doctors.

Conclusion: If their protests are answered, this will be catastrophic

Looking at the text as skeletoned, it is clear that this is a hybrid argument text type because of the through subtype earlier mentioned and the repeated structure of counter-argumentation: Cited thesis, Opposition and Substantiation. The writer presents her opponents' ideas/opinions/arguments and sets out to counter-argument them. This, as said earlier, was clear from the outset from the writer's statement of purpose. It is also clear that this is not the lop-sided subtype of counter-argumentation, nor the implicit subtype because respectively the former requires concession connectors such as 'although, despite, in spite of, etc.,', and the latter always does not signal that the proposition or argument in the cited thesis is the opponents'. Here, the writer explicitly signals and detaches himself from the propositions (cited theses) presented by using non-factive verbs such as 'claim (3) and say (2)'. These verbs are woven into the claim and are semantic open-category words. The signals used to indicate Opposition in the Arabic text are 'This is fabrication, I wonder, I say (2)'. This first signal is extremely explicit, whereas the others are explicit but less assertive. The substantiation evidence is drawn from personal and factual elements such as 'according to their documents, the law issued in 1985' and so on.

The major findings above are discussed in relation to the existing debate around argument structure.

\section{Discussion}

This contrastive rhetorical study was set out to examine firstly the features which 10 Arabic and 10 English argumentative editorials of the argumentation text type exhibit about their argumentation style, and secondly how these features compare between Arabic and English. Two daily newspapers which had local and international circulation or readership and had wide distribution were sampled. The editorails were subjected to quantitative and qualitative analysis and both graphical and textual representations yielded important findings in terms of macro and micro arguments. Drid (2014) studied the persuasive essays produced by advanced EFL Arab learners and found that out of 104 essays, 52 were of the through-argumentation style while 49 were followed the counter-argumentation mode. Further, Abbadi (2014) found that the 10 Arabic editorials he selected to follow through-argumentation and the 10 English editorials employed counter argumentation.

The current study is different in that it challenges existing scholarship in the area of argument structure in general and particularly in relation to editorials in that it introduces a hybrid rather than a static either-or, polarized model of argument structure. Therefore, in spite of the various findings emerging from the contrastive rhetoric analysis undertaken on the 20 Arabic and English editorials, the discussion below is directed towards one core point relating to the dichotomization of argument structure, which has not been studied thoroughly before.

Argument structure: Dichotomization versus Continua

Hatim (1991, 1997) and Hatim and Mason (1997) present a diagrammatical representation of argument structure which is re-printed below.

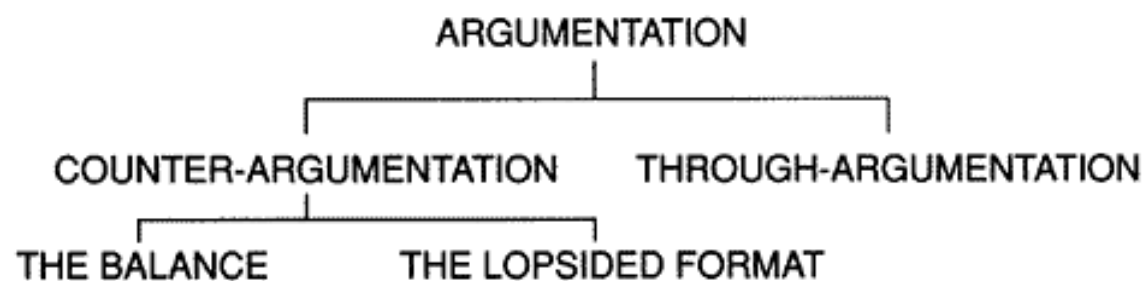

Figure 6.1. Hatim and Mason (1997, p. 107) Typology of Argumentation

As was indicated earlier, the above typology is overly simplistic and therefore has to be revised based on the findings of the current study:

- the above model (Figure 6.1) is overly restrictive and does not account for the fluidity of text types in the same texts as well as across; and

- current scholarship in argument structure in contrastive rhetoric consistently shows and describes a polarized view of argumentation type, either as through or counter (e.g., Abbadi, 2014 \& Drid, 2014).

In its place, the paper offers a more fluid and dynamic level of argumentation that should undergo testing and falsification. Therefore, Figure 6.1 above is reconfigured to Figure 6.2. 


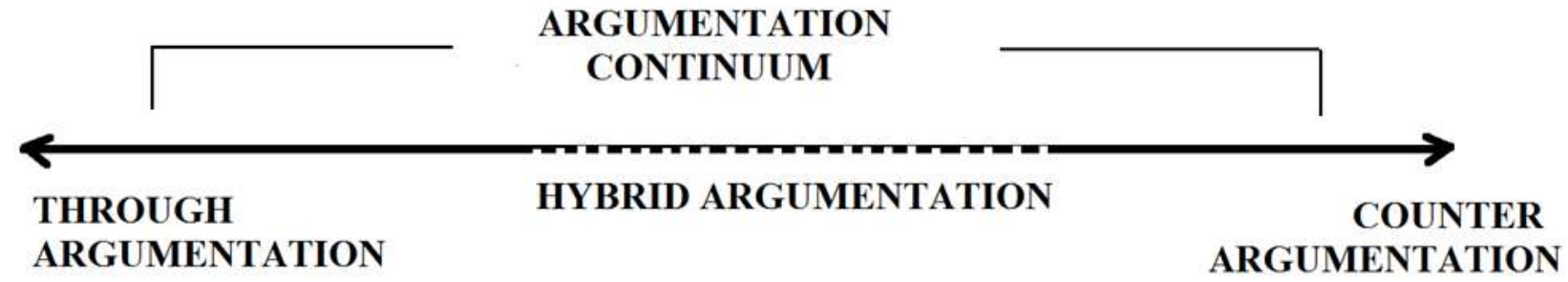

Figure 6.2. A Reconfigured Typology of Argumentation

The reconfiguration does not produce a typology; it is a continuum with two endpoints, through argumentation occupying one end, and counter argumentation occupying the second. The hybrid mode of argumentation in the centre of the pole exists to characterize argument structures that are a blend of two or more argumentation types. The above spectrum should be sufficient to characterize the argument structure of any argumentative text.

\section{Conclusion}

This comparative study of 20 argumentative Arabic and English editorials was set to analyze argument structure in editorials. Samples were selected from two daily newspapers with equally wide distribution, and were written by their native writers of Arabic and English. Graphical and textual analyses captured the argument structure in terms of macro and micro arguments. The study contributes to the existing literature by defying the polarized traditional purity model of argument structure and revives a more dynamic hybrid structure to understanding and analyzing arguments in Arabic and English. The study found out that instead of the editorials exclusively subscribing to one argumentation mode or the other, a third midway hybrid variant was necessary to characterize more accurately argument structure of some editorials. The analysis concluded the argument structure in the sampled editorials did not conform to the current predominant model, which tended to polarize argument structure in terms of through or counter argumentation.

A further significant finding pertains to the preferred argument structure. In the literature, the preferred mode of argumentation in English is the balance counter-argumentation, through-argumentation, and finally the lop-sided argument; in the current study, the editorials exhibited the order of through, explicit balance and lop-sided. In Arabic, the preferred order is cited to be through-argumentation, followed by lop-sided argument and finally the balance counter-argument. In the current study, the editorials exhibited through, explicit balance and lop-sided. In other words, the preferred mode of argumentation was the same in both the Arabic and English editorials (through first, counter second and lop-sided last), and for the analysis of both macrostructure and microstructure analysis and examination.

This textual examination of one genre of professional writing has implications for academic writing by way of the argumentation text types characterizing editorials. One way is for the second language instructor to sensitize students to possible ways arguments are structured in their L1 and possible ways of how to structure their arguments in L2.

\section{References}

Abbadi, R. (2014). The construction of arguments in English and Arabic: A comparison of the linguistic strategies employed in editorials. Argumentum, 10, 724-746.

Bell, A. (1991). The language of news media. Oxford: Basil Blackwell.

Bhatia, V. K. (1993). Nativization of job application-a microethnographic study. Paper presented at the International Conference in English in South Asia, Islamabad, Pakistan, 4-8 January, 1989.

Connor, U. (1996). Contrastive rhetoric: Cross-cultural aspects of second language writing. Cambridge: Cambridge University Press.

Dantas-Whitney, M. and Grabe, W. (1989). English and Brazilian Portuguese editorial prose. Paper presented at the 24th Annual TESOL Convention, San Antonio, TX, April, 1989.

de Beaugrande, R. (1980). Text, discourse and process: Toward a multidisciplinary science of texts. Narwood, NJ: Ablex.

de Beaugrande, R. \& Dressler, W. (1981). Introduction to textlinguistics. London: Longman.

Drid, T. (2014). Exploring the use of Through-argumentation and counter-argumentation in Arabic speaking EFL learners' argumentative essays. Arab World English Journal, 5(4), 336-352.

Flowerdew, J. (1993). An educational, or process, approach to the teaching of professional genres. ELT Journal, 47, 305-316.

Grabe, W. (1987). Contrastive rhetoric and text type research. In U. Connor and R. Kaplan (Eds.), Writing across languages, 115-137. Reading, MA: Addison-Wesley.

Grabe, W. and Kaplan, R. B. (1996). Theory and practice of writing. Pearson Education: Longman.

Hatim, B. (1991). The pragmatics of argumentation in Arabic: The rise and fall of a text type. Text ,11, 189-199. 
Hatim, B. (1997). Communication across cultures: Translation theory and contrastive text linguistics. Reed Hall: University of Exeter Press.

Hatim, B. and Mason, I (1997). The translator as communicator. London \& New York: Routledge.

Hoey, M. (1983). On the surface of discourse. London: George Allen and Unwin.

Hoey, M. (1994). Signaling in discourse: A functional analysis of a common discourse pattern in written and spoken English. In M. Coulthard (ed.) Advances in written text analysis, 26-45. London: Routledge.

Jenkins, S. and Hinds, J. (1987). Business letter writing: English, French and Japanese. TESOL Quarterly, 21, 327-349.

Leki, I. (1991). Twenty-five years of contrastive rhetoric: Text analysis and writing pedagogies. TESOL Quarterly, 19, 515-534.

Malah, Z., Tan, H. \& Rashid, S. M. (2016). Evaluating lexical cohesion in Nigerian newspaper genres: Focus on the editorials. International Journal of Applied Linguistics and English literature, 6(1), 240-256.

Raimes, A. (1983). Tradition and revolution in ESL teaching. TESOL Quarterly, 19, 535-552.

Ten, G. S. (1986). An applied discourse analysis of sales promotion letters. MA thesis submitted to the National University of Singapore, Singapore.

Toulmin, S. (1969). The uses of argument. London: Cambridge University Press.

Trikkonen-Condit, S. and Liflander-Koistinen, L. (1989). Argumentation in Finnish versus English and German editorials. In M Kusch and H. Schroder. Text-interpretation-argumentation, 173-181. Hamburg: Germany: Helmut Buske Verlage.

Zamel, V. (1983). The composing processes of advanced ESL students: Six case studies. TESOL Quarterly, 17, $165-187$.

\section{Appendix 1}

Results of the analysis of Argument structure in Arabic editorials

\begin{tabular}{|l|l|}
\hline A1 'Statues destruction and the process of decision-making in Taliban' \\
\hline Thesis to be argued & Decision-making in Taliban is influenced by many factors. \\
\hline Substantiation 1 & Little experience of leaderships \\
\hline Substantiation 2 & Lack of accumulation of experience \\
\hline Substantiation 3 & Religious aspect of movement is superior to political power \\
\hline Substantiation 4 & Independence of leadership means there is no negotiation \\
\hline Substantiation 5 & Absence of planning for future \\
\hline Substantiation 6 & Movement dominated by emotional ruling \\
\hline Substantiation 7 & Closed channels for dialogue with other countries \\
\hline Substantiation 8 & Absent of devices to collect information \\
\hline Conclusion & Decision-making in Taliban is haphazard. \\
\hline
\end{tabular}

\begin{tabular}{|l|l|}
\hline A3 'We and the world tourism publicity about Egypt' \\
\hline Thesis to be argued & $\begin{array}{l}\text { Reality of filmmaking in Egypt contradicts the Egyptian government attitudes towards } \\
\text { and support for tourism }\end{array}$ \\
\hline Substantiation 1 & Red tape and exaggeration regarding filmmakers from outside Egypt \\
\hline Substantiation 2 & Costs in Tunisia costs 5\% compared to costs imposed by Egypt \\
\hline Substantiation 3 & Requirement of numerous licences and permissions which take minutes in Tunisia \\
\hline Substantiation 4 & Foreigners entering Egypt land may be suspected of spying activity \\
\hline Substantiation 5 & Internet and satellite may provide the minute details about any city in Egypt \\
\hline Conclusion & $\begin{array}{l}\text { We need to keep abreast with technological advancement to support filmmaking and } \\
\text { tourism industry. }\end{array}$ \\
\hline
\end{tabular}

\begin{tabular}{|l|l|}
\hline A6 'Rules to protect our civilization' \\
\hline Thesis to be argued & The Egyptian Street does not tell of any civilization. \\
\hline Substantiation 1 & It saddens us to hear tens of abuses daily \\
\hline Substantiation $\mathbf{2}$ & Another sign is the packing up of sidewalks with cargoes of ships \\
\hline Substantiation 3 & I add to this the habit of throwing garbage in the streets \\
\hline Substantiation 4 & Lining up in queues does not exist. \\
\hline Substantiation 5 & There is also the habit of spitting in the streets \\
\hline Conclusion & $\begin{array}{l}\text { We need to hold tight to our values so that it is not said that the Egyptian civilization is } \\
\text { seasonal. }\end{array}$ \\
\hline
\end{tabular}




\begin{tabular}{|l|l|}
\hline A8 'Is this the start of collapse?' \\
\hline Thesis to be argued & Evidence suggests that American society is not holding together. \\
\hline Substantiation 1 & Drug addiction is an ever perennial issue until today. \\
\hline Conclusion & Drugs are an internal not an external issue in American society. \\
\hline
\end{tabular}

\begin{tabular}{|c|c|}
\hline \multicolumn{2}{|c|}{ A10 'You have life ... in dialogue' } \\
\hline Thesis to be argued & Refusal of dialogue and holding blindly to one's opinion is a barrier to advancement. \\
\hline Substantiation 1 & Dialogue is first sign of any society's advancement. \\
\hline Substantiation 2 & Each individual is unique not only in colour but also in way of thinking \\
\hline Substantiation 3 & Every one of us has a distinguished opinion towards what happens around him \\
\hline Substantiation 4 & $\begin{array}{l}\text { Expressing one's opinion, rather than silence, qualifies a person to be a citizen of } \\
\text { society }\end{array}$ \\
\hline Substantiation 5 & Opinions must be based on true knowledge, not rumors and parroting \\
\hline Substantiation 6 & Opinion must be based on scientific knowledge and wise meditation \\
\hline Substantiation 7 & $\begin{array}{l}\text { Allowing other individuals the right to express their opinions is how decisions are } \\
\text { made }\end{array}$ \\
\hline Substantiation 8 & $\begin{array}{l}\text { Acceptance of others' opinions must be based on listening to opponents and discussing } \\
\text { those with them }\end{array}$ \\
\hline Conclusion & If we are not convinced with this abstract ideas, let us go back to our Islamic heritage. \\
\hline
\end{tabular}

\section{A2 'About the problem of natural treatment'}

I Thesis to be argued: The problem is practitioners of natural treatment do not admit that they are ancillary to the medical profession.

Substantiation 1: In the past they demanded that a final year added to their program, and were give this final year.

Substantiation 2: In the past, the demanded their institute change into college, and they were given this.

I Substantiation 3: Now they are making protests to work without the supervision of the medical doctor, which is a catastrophe if it is allowed to happen.

I

Substantiation 4: Worldwide, the medical team is headed by a medical doctor who has first responsibility for the welfare of patient.

I

Substantiation 5: Practitioners in natural treatment are ancillary staff as the case is in the UK and US

Thesis to be opposed: Practitioners of natural treatment study six years, one year less compared to students in College of Medicine

Opposition: This is fabrication.

Substantiation 1: They study four years and another training year

Substantiation 2: Medical doctor has to study 10 years

Thesis to be opposed: Practitioners of natural treatment claim to be prepared to work under any doctor but a medical doctor.

Substantiation: Specialist or medical doctors do not know the work of natural treatment practitioners

Thesis to be opposed: They say that their certificates are not equalized when they travel to the US.

Substantiation 1: The US system requires that the certificates of medical doctors be equalized

Substantiation 2: Other professions ancillary to medical doctors do not get their certificates equated.

Thesis to be opposed: They say ministerial decisions stipulate that they should be treated separately from medical doctors

Substantiation 1: Ministerial decisions are not the law, and the State Council declared that natural treatment practitioners are under the assignment of medical doctors.

Conclusion: If their protests are answered, this will be catastrophic 
A4 'The new Arabic system'

Thesis to be opposed: Although we greatly confide in Amro Moosa's ability to revitalize the Arab League

Opposition: But we should not put on him more load than he can.

Substantiation: Because the Secretary General and the Arabic League itself are limited to within the boundaries of the Arab countries.

I Thesis to be argued: Amro Moosa may succeed in revitalizing the Arabic League.

I Substantiation 1: His ability to be optimistic and not to surrender to hopelessness

I Substantiation 2: His ability to use transition to good use

I Substantiation 3: Permission received to reorganize Arabic League

I

I

Substantiation 4: Personal acceptance and welcome Moosa receive from Arabic leaders

- Substantiation 5: International circumstances pose challenging decisions for Arabs

Thesis to be opposed: Although it may seem difficult to attempt now to found a collective Arabic unity.

Substantiation: The threats that circle Arabs make this attempt a matter of existence and destiny

Thesis to be opposed: Although the issues that Arabs disagree with are deeper and more serious than these they agree on and reaching an agreement within themselves is even more difficult that with Israel.

Substantiation 1: Continuity in seeking to resolve such controversies is a must since loss of hope means Arabs scattering in a world of danger and challenges

Thesis to be opposed: Although the Arab League has failed to solve the Iraqi and Somali problems

Substantiation 1: There may be a chance, to preserve the Arabic unity ... to establish economic alliance.

Conclusion: The scene as a whole has some bright and dark sides, but Amro Moosa will expand on the positive side to make progress.

\section{A5 'Is this freedom or dissolution?'}

Thesis: The Egyptian TV is encroaching on our values.

1. Thesis to be opposed: The author of one serial allowed the characters to discuss sexual aspects explicitly in ways that writers do not.

Substantiation 1: books are a commodity that you have the choice to buy or not Substantiation 2: Television imposes itself on all Arab speaking countries

2. Thesis to be opposed: Characters in the serial imply that virginity is unimportant and girls may lose it

Opposition: Does TV think that doing so is a form of advancement and progress?

Substantiation: Let us bid farewell to our honour and morals

3. Thesis to be opposed: We suppose television is the religious guard of divine religions

Opposition: It is a colossal blunder of the television censorship which reprimand any writer trying to praise anyone of status

Substantiation 1: Censorship's first job is to protect the rights of the Egyptians.

Substantiation 2: The writer's first job is to protect the freedom of the people and stands before offences against it.

Substantiation 3: What life is if it is empty from the honour of man and his freedom

4. The most important characteristic of freedom is to refrain from hurting the freedoms of others because in so doing you are not free, but a wicked offender

Conclusion: We as writers need to stand firm against these attempts to contaminate our holy values. 


\section{A7 'The Israeli American alliance'}

Ihesis to be argued: American society is based on interests.

I Substantiation 1: The Israeli government understood this and used it to its advantage.

I Substantiation 2: Examples of two presidents who did not understand the interests' principle and were not as successful as they should have been

I Substantiation 3: Example of Clinton who was successful despite disreputable actions.

Thesis to be opposed \& opposition: The second claim which surrenders to the Israeli American divine alliance is a clear loss.

Substantiation 1: Didn't Sharon take leave from the US to execute his plan of terminating Palestinian range in 100 years?

Substantiation 2: And didn't the American administration itself intervened when Sharon surpassed his limits?

Conclusion: The consecutive failure of Arabs with Israel must not be understood to be the inseparable mystical relationship between Israel and America.

\section{A9 'Journalists and the protection of their rights in electronic property'}

Thesis to be argued: The rights of journalists writing via electronic media were not considered in the ongoing discussion about copyright law.

I Substantiation 1: Examining the current definition, writings of electronic nature are subsumed.

I

I Substantiation 2: Through modern technology, electronic publicity of materials spread greatly

I

I Substantiation 3: Injustice to journalists was taken up the western units of writers and journalists.

I Substantiation 4: If publisher income varied based on the media of publication so should the

I_compensation for the journalist

Thesis to be opposed: Publishers may claim that their electronic newspapers has not yet reached profit

Opposition: This claim is not acceptable

Substantiation 1: They pay journalists before newspapers begin to make profits

Substantiation 2: Statistics showing profit and gain are not easy to come by.

Conclusion: The presence of Ibrahim Nafea as head of journalists prophesizes of better achievements in the field of journalism.

Appendix 2

Results of Argument structure in English editorials

E1 'The US pulls back: The Clinton approach has been ditched'

\begin{tabular}{|l|l|}
\hline Thesis to be argued & $\begin{array}{l}\text { According to Bushmen, Clinton approach of involvement in Palestinian case was } \\
\text { overambitious. }\end{array}$ \\
\hline Substantiation 1 & US is disengaged from Palestine-Israeli crisis. \\
\hline Substantiation 2 & US is engaged in Iraq. \\
\hline Conclusion & $\begin{array}{l}\text { Going to Iran will make a difference to Middle-East, but US does not want to be } \\
\text { engaged. }\end{array}$ \\
\hline
\end{tabular}

E3 'Passion play: Easter offers secular inspiration too'

\begin{tabular}{|l|l|}
\hline Thesis to be argued & The truth is that in this country this weekend has not religious or spiritual significance. \\
\hline Substantiation 1 & A recent poll revealed that only $43 \%$ knew the meaning of Easter \\
\hline Substantiation 2 & Secular society finds Christian beliefs simply fantastical \\
\hline Substantiation 3 & $\begin{array}{l}\text { Crucifixion presents painful questions that even the innocent and virtuous are brutally } \\
\text { killed. }\end{array}$ \\
\hline Conclusion & Easter can still teach us about humans' most persistent dilemmas. \\
\hline
\end{tabular}




\begin{tabular}{|l|l|}
\hline E4 'When frustration erupts: The lesson of Oldham: politics must listen' \\
\hline Thesis to be argued & Sources of tension has sources which are not mysterious: race, poverty and police \\
\hline Substantiation 1 & The first is poverty. \\
\hline Substantiation 2 & Muslims are finding it harder to find their place in British society \\
\hline Substantiation 3 & Policing is another issue. \\
\hline Substantiation $\mathbf{4}$ & Mr Hewitt's statements that Asians are not the victims of hatred by the perpetuators \\
\hline Substantiation 5 & Media reports that Asian kids had declared their own n-go areas. \\
\hline Conclusion & It is time for politics to listen. \\
\hline
\end{tabular}

\begin{tabular}{|l|l|}
\hline E5 'Violence does not pay: Prague's lessons is that reform works best' \\
\hline Thesis to be argued & $\begin{array}{l}\text { The protesters and the World Bank have to confront tough questions regarding } \\
\text { violence and undelivered promises. }\end{array}$ \\
\hline Substantiation 1 & $\begin{array}{l}\text { Protest movement (exploited by minority anarchists; protest refused condemning } \\
\text { Molotov for cocktails thrown at police, violence discredits claimed peace of protest, } \\
\text { reform is the credible path not abolition, protest raised the profile of debt relief and } \\
\text { poverty reduction) }\end{array}$ \\
\hline Substantiation 2 & $\begin{array}{l}\text { The fund and bank are confronted with tough questions on the ability to deliver on } \\
\text { their promises (progress on dent relief agonizingly slow, countries on debt are paying } \\
\text { more for their debts than on health and education, indebted countries are still poverty- } \\
\text { stricken }\end{array}$ \\
\hline Conclusion & Debtors need to relieve debts on the back of the in debt governments. \\
\hline
\end{tabular}

E6 'The truth is still hidden: Crucial questions persist about Lockerbie'

\begin{tabular}{|l|l|}
\hline Thesis to be argued & The Lockerbie verdicts is a kind of closure, but it is not the end of the matter \\
\hline Substantiation 1 & The answer to the question "who did it?" remains incomplete. \\
\hline Substantiation 2 & The question "why" leads into even murkier waters. \\
\hline Substantiation 3 & What happens now is another open question. \\
\hline Conclusion & A public inquiry may be needed. \\
\hline
\end{tabular}

\begin{tabular}{|l|l|}
\hline E7 'In search of a new map' \\
\hline Thesis to be argued & The Middle East is in peril but not yet lost. \\
\hline Substantiation 1 & There is no outside power to sponsor such changes \\
\hline Substantiation 2 & Neither Syria nor Israel would gain anything by a wider war \\
\hline Substantiation 3 & Nor does it seem likely that Iraq will engage in a wider war \\
\hline Substantiation 4 & Middle-Eastern countries are frightened and perplexed. \\
\hline Substantiation 5 & Arabs Diplomats are only rushing to secure condemnation of Israeli acts. \\
\hline Conclusion & If the US does not intervene now, immediate upheaval will be the result. \\
\hline
\end{tabular}

E8 'Journey to nowhere: Vetoed: a mission that might have helped'

\begin{tabular}{|l|l|} 
Theses to be opposed & $\begin{array}{l}\text { 1. The reality of a dead Jewish baby and yet another slaughtered Arab child, } \\
\text { perhaps. } \\
\text { 2. Perhaps it is the political reality that encourages the suicide bombers of Hamas } \\
\text { and Islamic Jihad to commit daily atrocities with the aim of driving Israel into } \\
\text { insupportable overreaction. } \\
\text { 3. Or perhaps it is the political of the Amman Arab summit which ended yesterday } \\
\text { and which, seem from the Arab street, once again failed to provide a strong, united } \\
\text { lead in defending Palestinian rights. }\end{array}$ \\
\hline Opposition & No \\
\hline Substantiation 1 & $\begin{array}{l}\text { the political reality to which Mr Cunningham refers is that captured by official } \\
\text { photographers at the White House last night when Mr Sharon turned the charm on } \\
\text { George Bush. The US veto was one result of that equal encounter. }\end{array}$ \\
\hline Substantiation 2 & $\begin{array}{l}\text { Another is continuing American acquiescence in what Kofi Anan decries as Israeli } \\
\text { collective punishment of Palestinians. }\end{array}$ \\
\hline Substantiation 3 & $\begin{array}{l}\text { Yet another is Washington's tacit consent to allowing Mr Sharon to dictate the terms of } \\
\text { peacemaking. }\end{array}$ \\
\hline This is not political reality; it is gross political irresponsibility.
\end{tabular}

E9 'A failure of leadership: Sharon and Araft must stop posturing'

\begin{tabular}{|l|l|}
\hline Thesis to be argued & None of the leaders is trusting or can be trusted to return to peace talks. \\
\hline Substantiation 1 & Sharon has been more or less given free ride by Washington. \\
\hline Substantiation 2 & Arafat's position is irresponsible. \\
\hline Conclusion & Waiting for Israelis and Palestinians is not an option. The US must step in. \\
\hline
\end{tabular}


E2 'Simply the wrong policy: Bush's energy plans are for a different era'

Thesis to be argued: Bush's energy plans of focusing on traditional energy than nuclear energy are wrong.

Cited Thesis 1: The US need to expand energy supplies and provide electricity

Opposition: But it does not need to build new nuclear, gas and coal fired stations

Substantiation 1: $21^{\text {st }}$ century is about harnessing renewable energy resources.

Substantiation 2: The US will enrage other countries signing up to Kyoto agreement, and give the rest of the world a competitive edge in developing alternative sources.

Cited thesis 2: Even if nuclear plants safety problems can be overcome

Opposition: The objection to nuclear plants is this.

Substantiation: Nuclear plants require hefty payments from the taxpayer.

Substantiation: The Bush proposals will rightly face opposition from Democrats and environmentalists.

Cited thesis 3: Provisions in proposals have been carefully worded to require only 20 out of 105 votes.

Opposition \& Substantiation: But that is enough to make a battlefield.

Conclusion: If half the funding given to fossil fuel energy is given to nuclear energy development, then the US attitudes may be different.

\section{E10 'Supping with Sharon: Rules for dealing with Israel's new leader'}

Thesis to be argued: Dealing with the disreputable Sharon is not clear-cut.

Cited thesis 1: Mr Sharon is no dictator, no midnight coup leader. He is Israel's democratic choice.

Opposition: Is it open for outsiders to validate people's decision?

Substantiation: George Bush, Vladimir Putin and Jiang Zemin are responsible for equal power abuses.

Cited thesis 2: Mar Sharon says he is a changed man. People who believe in forgiveness should give him a chance.

Opposition: But then, consider the political realities.

Substantiation 1: Only $4.5 \mathrm{~m}$ voted for Sharon.

Substantiation 2: Israel is such a divided society that it has lost its confidence in peace.

İ́Substantiation 1: Those who judge Sharon must also judge themselves

Substantiation 2: The Israeli left and the Palestinians are to blame for the state of affairs.

Conclusion: The Middle-East needs tough-minded honest brokers capable of facing Sharon. 